\title{
UC1 Oscillator Remote Lab for Distant Electronics Education
}

\author{
http://dx.doi.org/10.3991/ijim.v9i2.4375 \\ Saida Latreche, Zehira Ziari and Smail Mouissat \\ Université Constantine 1, Constantine, Algeria.
}

\begin{abstract}
In this paper, we are interested in the transformation of a face-to-face active course into a web-based active course. Indeed, distance education has been rapidly become more important around the world due to the development of Information and Communication Technology.
\end{abstract}

However, the roles of these later must evolve to accommodate these new models, with increased student responsibility and accountability.

First, we reports on the experience of Constantine1 University in the development of 'Electric oscillator circuit' on-line course via the Moodle platform. We describe the different stages of the online course and highlight its possibility, which is not available in the face-to-face courses.

Second, we present the remote lab of UC1 University, which is developed under eSience project. It aims to develop remote labs in the Maghreb country and to link them.

Therefore, we focus on the implementation of 'Wien Bridge Oscillator' experiment, which is deployed on the interactive version of iLab Shared Architecture (ISA).

Index Terms-eLearning, ISA, LabVIEW, oscillator experiment, remote laboratories.

\section{INTRODUCTION}

The remote laboratory is an automated laboratory where students can experiment to find out the physical phenomena. The experiment in the remote lab is a real physical setup. In many engineering domain, where education includes laboratory work unit, the students must go to the site of the practical experiences. The concept of remote laboratory overcomes not only the problem of place inconvenience, but also the problem associated with practical work schedules [1,2, and 3]. This new possibility to perform remote experiments laboratory allows a more flexible learning and teaching and also increases the means of learning presentation. Indeed, a teacher can achieve by this way real demonstrations, without moving the presented experience.

Elab is the result of a development, which began at the end of the 90th in the framework of remote laboratory.

From this date, many experiences have been emerged; we can cite especially the Ilab Shared Architecture (ISA) developed by MIT (Massachusetts Institute of Technology) team in August 2008. It uses the web services of the Microsoft windows platform [2, 4].

Later, in 2010 the Carinthia University of Applied Science team (Austria) has also developed an image pro- cessing online lab within the ISA too [5]. Then, in 2013, a java implementation of the batched ilab ISA has been developed by university of Queensland team [6].

Therefore, UC1 team adapted the ilabs Shared Architecture (ISA) for our remote experiments. The ISA is a web service infrastructure, which permits the access to a large variety of online laboratory [5]. It is produced by three software modules: the Labserver, which realizes a physical connection to the laboratory hardware, the User Interface (Client: students in our case) and the Service Broker (communication between the Client and the Labserver). The Service Broker generates multi services like authentication, user registration...

On another hand, many universities have been working for many years on the development of its courses to be delivered on the Internet known as the e-learning.

In this paper we illustrate our Remote Laboratory (UC1 eLab) deployed on the interactive version of iLab Shared Architecture (ISA) [2, 4] and the corresponding course implemented on a Moodle platform.

This remote lab is developed under eSience project. This later is a 'euro-maghrebin' project financed by the European community. It aims to develop and link remote lab in the Maghreb country (Algeria, Tunisian and Morocco Universities) and to link them.

\section{THE CORRESPONDING ONLINE COURSE}

This eLab is the consequence of eSience Project which is a Tempus euro-Mediterranean project (2013-2015). Indeed, UC1 (University Constantine1) team has developed a remote lab which is the first remote laboratory at UC1 University and the first in Algeria.

To improve this eLab, we have also developed on-line corresponding courses. In this paper, we present the 'Electronic Principal Functions (FPE): The oscillators' course. The full module has a total weight of 7 ECTS credits and its aim is to permit to the Master1 student of electronics to develop knowledge of oscillator circuit. At the end of this UE ('Unité d'Enseignement' : study Unit), the student must be able to embed an oscillator and to optimize the amplifier and the feedback circuit for an optimal frequency.

We Use the Moodle (Modular Object-Oriented Dynamic Learning Environment) [7] platform which is very appropriate for distant education. The Fig. 1 presents the login page of the online course.

We give an account to all registered students and allow them to access to the areas courses and tutorials. 


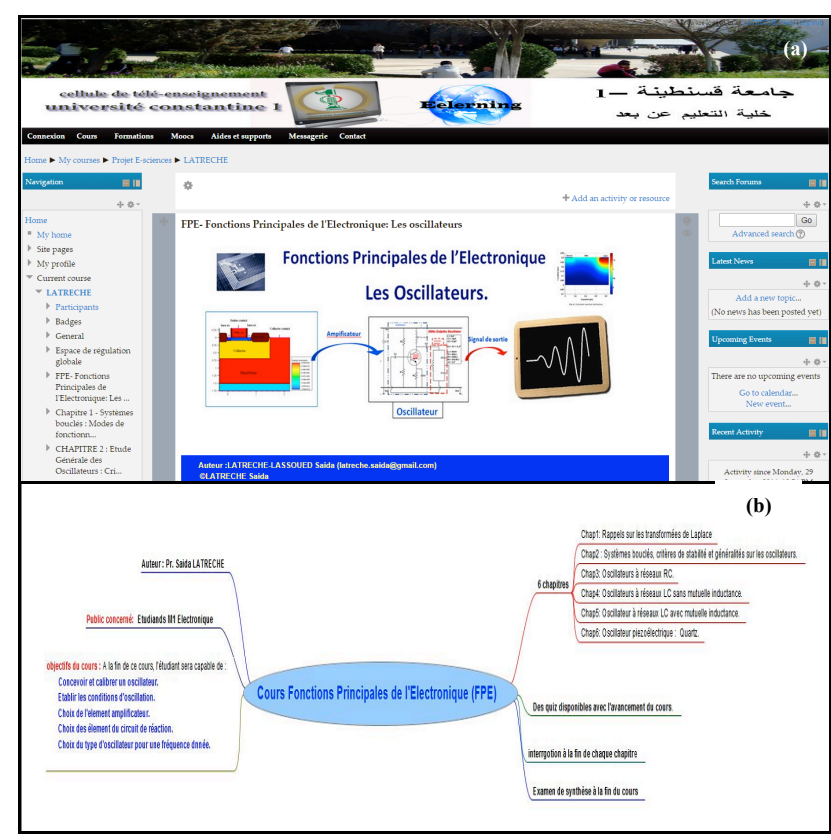

Figure 1. a-Login page of the FPE Course and $b$ - the presentation of the course

Therefore, they consult in an interactive way the different resources. In addition, through forums and virtual meeting rooms, students are continuously in contact with the teacher. Constant assessment is carried out through:

- Quizzes,

- QCM, QCS,

- Homework.

Ongoing evaluations permit to detect possible weaknesses in understanding and to remedy immediately.

\section{Design AND CONSTRUCtion OF THE REMOTE LABORATORY}

The experimental setup (e-TP) used for the practical work of the 'Electronic Principal Functions (FPE): The oscillators' course are instrumented and controlled by computer, thanks to graphic interfaces. Therefore, it was relatively easy their adaptation to a remote manipulation by adding a communications module and image acquisition devices and sound.

Among the practical works of this course, one practice will be tested, which is the Wien bridge oscillator.

The Wien bridge oscillator is a device that produces low frequency quasi-sinusoidal oscillations without having a sinusoidal input source. This type of oscillator is widely used in commercial generator.

The Wien bridge oscillator is an oscillator, which uses a Wien network in the feedback chain. The operational amplifier used in this oscillator circuit is working as noninverting amplifier mode. The aim of the remote practice is to study and calculate Wien bridge oscillations frequency. The produced sine wave has a frequency depending on $\mathrm{R}$ and $\mathrm{C}$ of the feedback circuit at operation DC power supply up to $12 \mathrm{~V}$. The oscillation frequency is given by:

$$
f_{o}=\frac{1}{2 \pi R C}
$$

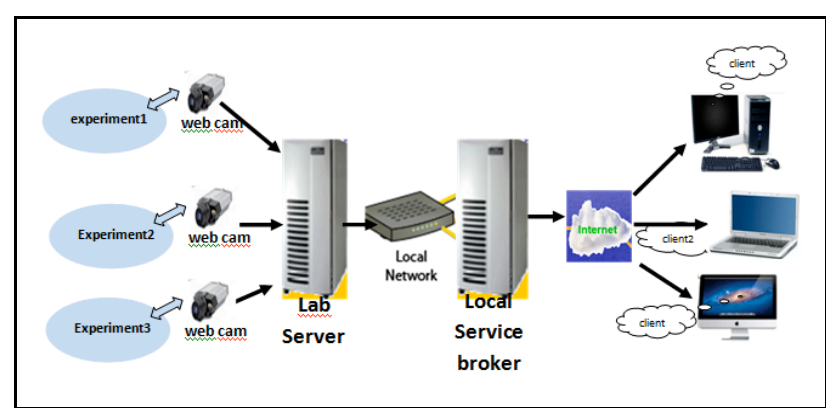

Figure 2. UC1 elab architecture.

\section{A. The eLab Architecture scheme}

Client server architecture was developed to enable collaborative work $[5,8]$. The server is a computer equipped with necessary material to pilot the experience. This includes an acquisition system, a camera and a set of software (LabVIEW and drivers for control and signal acquisition). The server operates a list of customer requests (remote students) in order to use the system material optimally. It sends the results to the client. The client is a computer equipped with different functionalities, which enable the observation and the setting of the experiment remotely. The client application is a virtual instrument (VI) compiled for the chosen platform. After carrying out the experiment at the server, the remote client downloads the measurement results. Then, the student can analyze and discuss the experimental data in concordance with the theory.

Three modules are needed to build the client and server applications: the Labserver, the User Interface and the Service Broker.

In our case, the developed architecture is shown in Fig. 2. In addition to User interface, the system consists of:

- The Interactive Service Broker is the heart of the ISA. The Service Broker provides generic administrative services, such as authentication the user, authorization, reservation, data storage, user management, launching labs and for the preservation of the lab session with the considered laboratories [9, 10 and 11]. Therefore, the service broker has to communicate with the scheduling services, because they keep all data of the available time blocks in a laboratory and about user rights and reservations $[12,13]$.

- Web server, IP camera and several computers on the client side control a web Labserver that consists to realize a physical connection to the experimental module KL 200 (experiment1). The Lab server communicates with the service broker via the web server $[13,14]$.

\section{B. User Interface}

The students can access the remote lab through the laboratory's web interface, so they can manage their experiments. To get access to the eLab, the user must first authenticate himself. A login page will appear to permit to the student his identification by a username and a password (Fig. 3). 


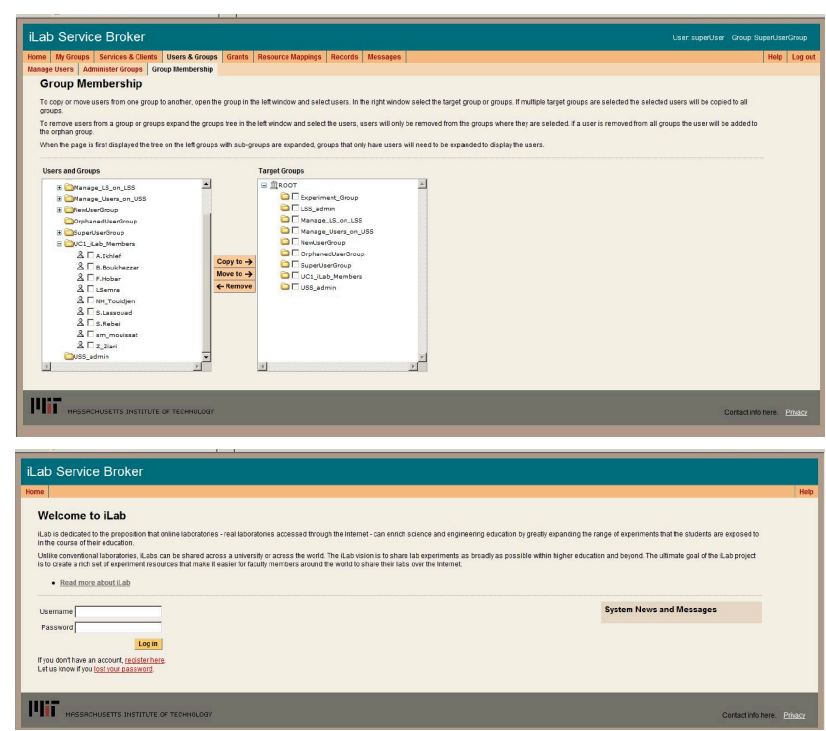

Figure 3. Service Broker, login page.

After logged-in, the user can reserve for the chosen experiment. The date and time for this later can be picked from a schedule table.

\section{PSpice Simulation}

The simulation of the feedback circuit was performed by means of the Electronics Workbench Professional simulator, based on the PSpice software.

In Fig. 4 are shown both the gain in tension and the shift phase as a function of the feedback circuit frequency. The resonance frequency $\left(f_{0} \sim 700 \mathrm{~Hz}\right)$ is deduced from the maximum of the gain, which indicates a zero phase.

\section{Practical Part (remote part)}

Fig. 5 shows a typical Wien bridge oscillator design based on experimental module KL 200 [15].

There are different types of tools to implement the online laboratories. However, the LabVIEW 8.6 software (Laboratory Virtual Instrumentation Engineering Workbench) is used for remote control of equipment. It is a platform and development environment for a graphical programming language from National Instruments [16]. The LabVIEW software is installed in the OnlineLab Lab Server which controls the whole system. In our case, we use the LabVIEW platform for both the student control interface and the control of the hardware. The connection system and communication GPIB/BUS National Instrument connected to the computer USB ports is compatible with the equipment used in this practical experiment such as Agilent 33220 generator, equipped with a GPIB connection and digital oscilloscope Agilent DSO6012A, equipped with a GPIB connection. Once connected to server, students can control real experimental equipment using a visual interface. In this case, the student chose his manipulation through the student interface as shown in Figure 7 (e g, Wien bridge oscillator circuit) and all parameter settings (amplitude and frequency of the input signal). The virtual instrument (VI) front panel gives the students the ability to control the experiment. Students can follow a series of instructions to measure the amplitude of the output signal and the temporal shift between the input and output signals to estimate the phase shift introduced by the feedback circuit for different frequencies. Students

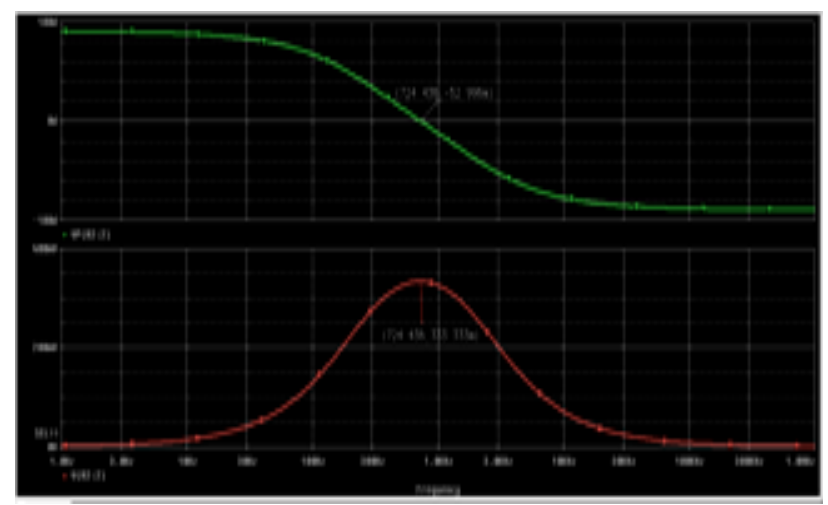

Figure 4. Response frequency simulation.

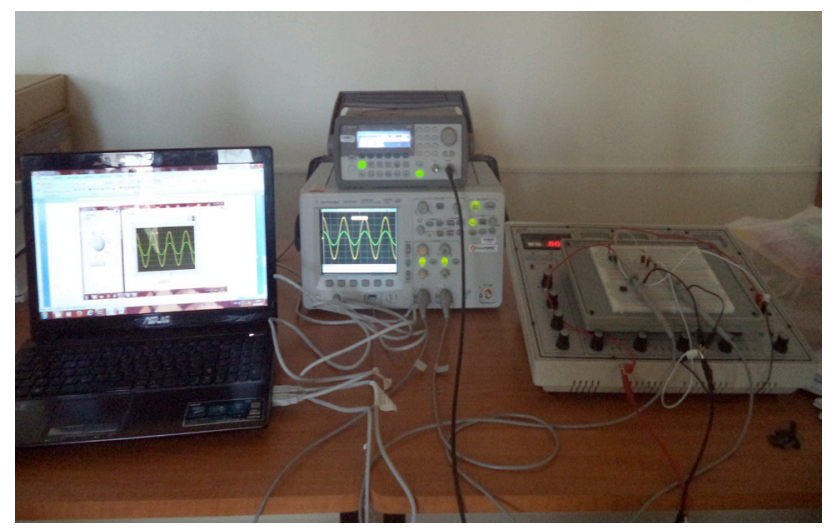

Figure 5. Wien bridge oscillator.

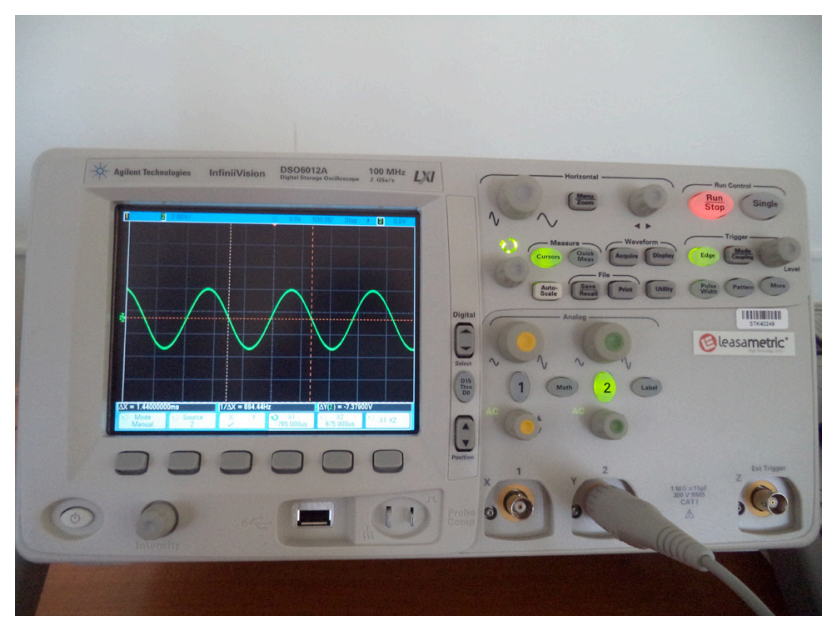

Figure 6. Output signal of the Wien Bridge oscillator.

can after visualize the output signal generated by Wien bridge oscillator. With the use of diodes, the non-ideal operational amplifier can produce steady oscillations. Given the measurement results (the gain and phase response versus frequency and the oscillator output signal), students analyzes and interprets experimental measurements, in link with the theory of sinusoidal oscillators and writes a report which will be evaluated by the teacher. He deduces the essential characteristics of the feedback circuit and the Wien bridge oscillator; such as its oscillation frequency, attenuation, phase shift and sine wave output signal Vs $(\mathrm{t})$.

The obtained oscilloscope signal (Fig. 6) showed a sinusoidal form. Its frequency is about $700 \mathrm{~Hz}$. 


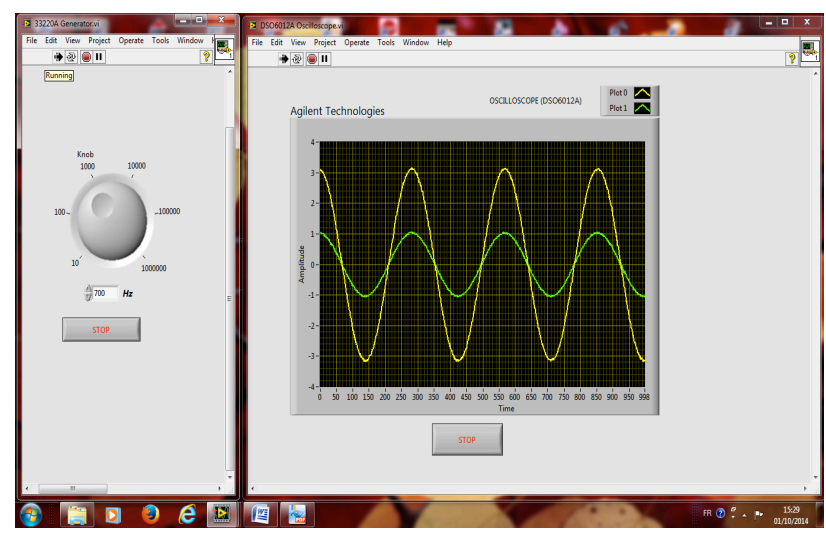

Figure7: Graphical user interface.

\section{CONCLUSION}

Laboratory experiment is important for engineering and science students, to understand theoretical courses, as well as to prepare them for their professional career.

In this paper, we presented both a general architecture of UC1eLab for the remote implementation of practical laboratory experiment in the field of electronics and the corresponding on-line courses. Our remote lab is controlled by LabVIEW software and used acquisition interfaces as GPIB or DAQ mx 6008.

The construction of the remote laboratory on electronic oscillator circuits will enable students to experiment on specific characteristics of oscillators. A Wien Bridge Oscillator has been considered. The remote part of the experiment has demonstrated a good agreement with the PSpice simulation one.

In the future, we intend to further develop this remote lab in the aim to link the chain of experiments developed in the project Tempus eSience by Algerian, Tunisian and Morocco labs.

\section{REFERENCES}

[1] T. Zimmer, M. Billaud, and D. Geoffroy, "A remote laboratory for electrical engineering education," IMCL2006, April 19-21, 2006 Amman, Jordan.

[2] V.J. Harward, J.A. del Alamo, S.R. Lerman, P.H. Bailey, "The iLab Shared Architecture: A Web Services Infrastructure to Build Communities of Internet Accessible Laboratories," Proceedings of the IEEE , vol. 96, no.6, pp.931-950, June 2008 http://dx.doi.org/10.1109/JPROC.2008.921607

[3] MIT iLab URL: https://wikis.mit.edu/confluence/display/ILAB2/ Home - Last visited in 03/2010.

[4] iLab Downloads - iLabs Dev- MIT Wiki Service https://wikis.mit.edu/confluence/display/ILAB2/iLab+Downloads.

[5] Michael Niederstätter, Thomas Klinger and Danilo Garbi Zutin, "An Image Processing Online Laboratory within the iLab Shared Architecture", iJOE- vol. 6, Issue 2, May 2010, http://dx.doi.org/10.3991/ijoe.v6i2.1289
[6] L.J. Payne, M.F. Schulz, "JAVA Implementation of the Batched iLab Shared Architecture", iJOE - vol. 9, Special Issue 3: "REV2013", April 2013, http://www.i-joe.org.

[7] Moodle Services. (2004). Welcome to the Moodle Service Network![Online]. Available: http://moodle.com/

[8] S.R. Williams, R. Blanchard, A. Mohammed, M. Bliss, R. Pancholi, M. Clowes,"The Development of a Remote Laboratory for Distance Learning at Loughborough University," Proceedings of EDULEARN13 Conference, 1st-3rd July 2013, Barcelona, Spain, pp. 4342-4349.

[9] J.L. Hardison, K. DeLong, P.H. Bailey and V.J. Harward, "Deploying Interactive Remote Labs Using the ILab Shared Architecture," $38^{\text {th }}$ IASEE/IEEE Frontiers in Education Conference, October 22-25, 2008, Saratoga Springs, NY, S2A pp. 1-6.

[10] K. DeLong, V.J. Harward, P. Bailey, J. Hardison, G. Kohse, Y. Ostrocsky, "Three Online Neutron Beam Experiments Based on the iLab Shared Architecture", IEEE Education Engineering (EDUCON), Madrid, Spain pp . 145-150, 14 - 16 April 2010.

[11] A. Naddami, A. Fahli, M. Gourmaj, M. Moussetad, "Determination of Synchronous Machine Parameters using iLab Shared Architecture," iJOE, vol. 10, Issue 3, 2014, pp. 18-23.

[12] O. Akinwale, L. Kehinde, K. Ayodele, A. Jubril, O. Jonah et al. (2009). "A LabVIEW- based On - Line Robotic Arm for Students' Laboratory," ASEE, Austin, TX, June 14, 2009.

[13] M. Niederstätter, T. Klinger and D.G. Zutin, "An Image Processing Online Laboratory Within the ILab Shared Architecture," iJOE vol. 6. Issue 2, May 2010, pp. 37-40.

[14] J. Hardison, D. Zych, J.A. del Alamo, V.J. Ha rward, S.R. Lerman, S.M. Wang, K. Yehia, C. Varadharajan, " The Microelectronics Weblab 6.0 - An Implementation Using Web Services And The ILab Shared Architecture," in Proceedings of the Conference on Exploring Innovation In Education And Research, Tainan, Taiwan, 2005.

[15] KL-200 Linear circuit LAB teacher handbook.

[16] http://en.wikipedia.org/wiki/LabVIEW

\section{AUTHORS}

Saida Latreche is with the 'Laboratoire Hyperfréquences et Semi-conducteurs' of Electronics Department of Constantine 1 University, Constantine 25000, Algeria. (e-mail: latreche.saida@gmail.com).

Zehira Ziari is with the 'Laboratoire de Microsystèmes et Instrumentation' of Electronics Department of Constantine 1 University, Constantine 25000, Algeria. (email: zziari_zahira@yahoo.fr).

Smail Mouissat is with the 'Laboratoire de Microsystèmes et Instrumentation' of Electronics Department of Constantine 1 University, Constantine 25000, Algeria. (email:sm_mouissat@hotmail.com).

This project has been funded with support from the European Commission. This publication reflects the views only of the authors, and the Commission cannot be held responsible for any use, which may be made of the information contained therein. Manuscript received 12 January 2015. Published as submitted by the authors 23 March 2015. 